\title{
Cost-Utility Analysis of Vasoconstrictors Plus Albumin in the Treatment of Thai Patients with Type I Hepatorenal Syndrome
}

\author{
Sermsiri Sangroongruangsri ${ }^{1}$ \\ Kankamon Kittrongsiri ${ }^{2}$ \\ Phunchai \\ Charatcharoenwitthaya $^{3}$ \\ Abhasnee Sobhonslidsuk (iD ${ }^{4}$ \\ Usa Chaikledkaew ${ }^{1,5}$ \\ 'Social and Administrative Pharmacy \\ Division, Department of Pharmacy, \\ Faculty of Pharmacy, Mahidol University, \\ Bangkok, Thailand; ${ }^{2}$ Social, Economic and \\ Administrative Pharmacy (SEAP) \\ Graduate Program, Department of \\ Pharmacy, Faculty of Pharmacy, Mahidol \\ University, Bangkok, Thailand; ${ }^{3}$ Division \\ of Gastroenterology, Department of \\ Medicine, Faculty of Medicine Siriraj \\ Hospital, Mahidol University, Bangkok, \\ Thailand; ${ }^{4}$ Division of Gastroenterology \\ and Hepatology, Department of \\ Medicine, Faculty of Medicine \\ Ramathibodi Hospital, Mahidol \\ University, Bangkok, Thailand; ${ }^{5}$ Mahidol \\ University Health Technology \\ Assessment (MUHTA) Graduate \\ Program, Mahidol University, Bangkok, \\ Thailand
}

Correspondence: Usa Chaikledkaew Social and Administrative Pharmacy Division, Department of Pharmacy, Faculty of Pharmacy, Mahidol University, 447 Sri-Ayudhaya Road, Rajathevi, Bangkok, 10400, Thailand

Tel +662-644-8679 ext 5317

Fax +662-644-8694

Email usa.chi@mahidol.ac.th
Purpose: Type 1 hepatorenal syndrome (type 1 HRS) or hepatorenal syndrome-acute renal injury (HRS-AKI) leads to high short-term mortality rates in patients with cirrhosis. Vasoconstrictor therapy effectively improves survival of these patients and has been a bridge to liver transplantation. The aim of this study was to assess the cost-utility of terlipressin plus albumin $(\mathrm{T}+\mathrm{A})$ and noradrenaline plus albumin $(\mathrm{N}+\mathrm{A})$ compared to best supportive care (BSC) for treating type 1 HRS patients in Thailand.

Methods: A cost-utility analysis using a six-state Markov model was performed from societal and payer perspectives over a lifetime horizon. The clinical outcomes, costs, and utility parameters were obtained from literature, network meta-analyses, and expert opinion. One-way and probabilistic sensitivity analyses were conducted to account for uncertainty.

Results: The $\mathrm{T}+\mathrm{A}$ yielded the highest cost (848,325 Thai Baht (THB)) and health outcomes (2.82 life-years (LY) and 2.27 quality-adjusted life-years (QALY)). Compared to BSC, incremental cost-effectiveness ratios (ICERs) of the $\mathrm{T}+\mathrm{A}$ and $\mathrm{N}+\mathrm{A}$ were 377,566 and 412,979 THB per QALY gained, respectively. If $\mathrm{N}+\mathrm{A}$ is administered outside the intensive care unit, the ICER was 308,964 THB per QALY. The treatment cost after liver transplantation from year 3 onwards was the most influential factor for ICERs, followed by the cost of terlipressin, duration of noradrenaline treatment, and cost of albumin. At the Thai societal willingness-to-pay threshold of 160,000 THB per QALY gained, the probabilities of being cost-effective for $\mathrm{T}+\mathrm{A}, \mathrm{N}+\mathrm{A}$, and $\mathrm{BSC}$ were $11 \%, 20 \%$, and $69 \%$, respectively.

Conclusion: The $\mathrm{T}+\mathrm{A}$ and $\mathrm{N}+\mathrm{A}$ treatments would not be cost-effective compared to BSC in the Thai setting.

Keywords: terlipressin, noradrenaline, HRS-AKI, liver transplantation, economic evaluation, Thailand

\section{Introduction}

Hepatorenal syndrome (HRS) is a life-threatening acute kidney injury (AKI) leading to a severe renal function decline particularly in patients with advanced cirrhosis and ascites. ${ }^{1,2}$ The incidences of HRS in cirrhosis patients and liver transplant candidates were $8-40 \%{ }^{3,4}$ and $48 \%$, respectively. ${ }^{5}$ A population-based study reported low annual prevalence rates of HRS during 2003-2013 ranging from $1.5 \%$ to $1.9 \%$ with an increasing trend over time. ${ }^{6}$ However, HRS caused the highest mortality rate and the longest hospitalization among cirrhosis-related complications in Thailand. ${ }^{7}$ It was also considered as the most significant predictor of in-hospital death among hospitalized cirrhotic patients. These patients with HRS 
were approximately 5 times more likely to develop inhospital mortality than those without such complication (mortality rate 36.9\%; odds ratio, 5.04; 95\% confidence interval (CI), 4.38-5.79). ${ }^{6}$ Type $1 \mathrm{HRS}$, which is currently renamed as $\mathrm{HRS}-\mathrm{AKI}^{8}$ is a severe subtype of HRS which has a dramatically poor prognosis with a median survival of about 2 weeks. ${ }^{9}$ The prevalence of type 1 HRS was $2.6 \%$ of patients with cirrhosis. ${ }^{10}$

Although liver transplantation (LT) is likely to be the definitive treatment for both type 1 and type 2 HRS or HRSNAKI (ie, HRS-Non AKI), the shortage of liver organs has been a major obstacle and the majority of patients awaiting LT died from type 1 HRS. ${ }^{1,11}$ A pharmacologic treatment, as a bridge to LT, might potentially reverse renal function and improve survival in patients with type $1 \mathrm{HRS}$ on the waiting list. $^{11,12}$ Systemic vasoconstrictor therapy combined with albumin, a plasma volume expander, has been considered as the first-line treatment. It improves renal and liver functions, alleviates portal hypertension, and increases systemic arterial pressure in patients with cirrhosis and HRS. The European Association for the Study of the Liver (EASL) recommended terlipressin in combination with albumin $(\mathrm{T}$ $+\mathrm{A})$ as the drug of choice. ${ }^{11}$ This treatment improved renal function in $40-50 \%$ of patients with type $1 \mathrm{HRS}^{2}$ and increased short-term survival even recurrence occurred in about half of patients with complete response (CR). ${ }^{13}$ The $\mathrm{T}+\mathrm{A}$ therapy had a higher rate of HRS reversal and improve serum creatinine ( $\mathrm{SCr}$ ) level compared to albumin monotherapy or placebo. However, its ischemic event rate was significantly higher than the others (risk ratio (RR), 3.56; 95\% CI, 1.64-7.72). ${ }^{14}$ Noradrenaline or midodrine plus octreotide has been recommended as alternative therapies to terlipressin; however, evidence supporting these treatments in patients with type $1 \mathrm{HRS}$ is limited. ${ }^{11}$ Noradrenaline has equal efficacy (RR of 30-day survival, 1.04; 95\% CI, 0.841.30 and RR of HRS reversal, 1.03; 95\% CI, 0.81-1.31) and is much cheaper than terlipressin, ${ }^{15}$ however, it should be administered in intensive care units (ICU).

In Thailand, there is no treatment for type 1 HRS available in the National List of Essential Medicines (NLEM), which is the reimbursement drug list for the public health insurance schemes. A treatment using midodrine plus octreotide has not been available for Thai patients. Terlipressin has been used off-label with albumin for sustaining patients' lives with type 1 HRS who on the waiting list on LT. Only the Civil Servant Medical Benefit Scheme (CSMBS) beneficiaries (approximately $8 \%$ of the Thai population) can get reimbursement for such expensive treatment, while other patients who could not afford the drug therapy underwent the best supportive care (BSC). There is no economic evaluation study of the vasoconstrictor therapies for type $1 \mathrm{HRS}$ patients, which incorporate LT into the model to reflect the long-term benefit of such treatments. Therefore, this study aimed to evaluate the cost-utility of $\mathrm{T}$ $+\mathrm{A}$, noradrenaline plus albumin $(\mathrm{N}+\mathrm{A})$, compared to BSC (placebo or albumin) for Thai patients with type 1 HRS who might be eligible for LT.

\section{Materials and Methods}

\section{Target Population}

The target population was decompensated cirrhotic patients (Child-Pugh class B/C) with type 1 HRS aged 40 years and over in Thailand. The HRS could occur among these patients while waiting for liver transplantation.

\section{Model Structure}

The cost-utility analysis (CUA) using a Markov model was performed based on societal and payer perspectives. Costs and health outcomes were evaluated over a patient's lifetime horizon, which was approximately 20 years. As the time horizon was longer than one year, the discount rate of 3\% per annum was applied for all future costs and outcomes according to the guidelines for health technology assessment in Thailand. ${ }^{16,17}$

The Markov model with a 15-day cycle length comprised 6 health states based on the natural history of the disease (Figure 1). The arrows in Figure 1 represent transition probabilities and indicated the options for patients transitioning to other health states, including death state or to be in the same health state. All hypothetical patients with decompensated cirrhosis who developed type 1 HRS for the first time would start at the 1 st occurrence of type 1 HRS state (1st type 1 HRS). After these patients received the treatments, they would proceed to the state of partial response (or partial HRS reversal), decompensated cirrhosis with a complete HRS reversal state, or death. Patients with partial HRS reversal might be in the same health state, completely recover to decompensated cirrhosis, or death. The patients with complete HRS reversal might be in the same health state or would move to the 2 nd occurrence of type 1 HRS (2nd type 1 HRS or HRS relapse) state, LT, or death. The patients experiencing an HRS relapse would be able to move to the complete HRS reversal state or death state. Once patients undergo LT, they might be in that health state or death. The death state was an absorbing state in 


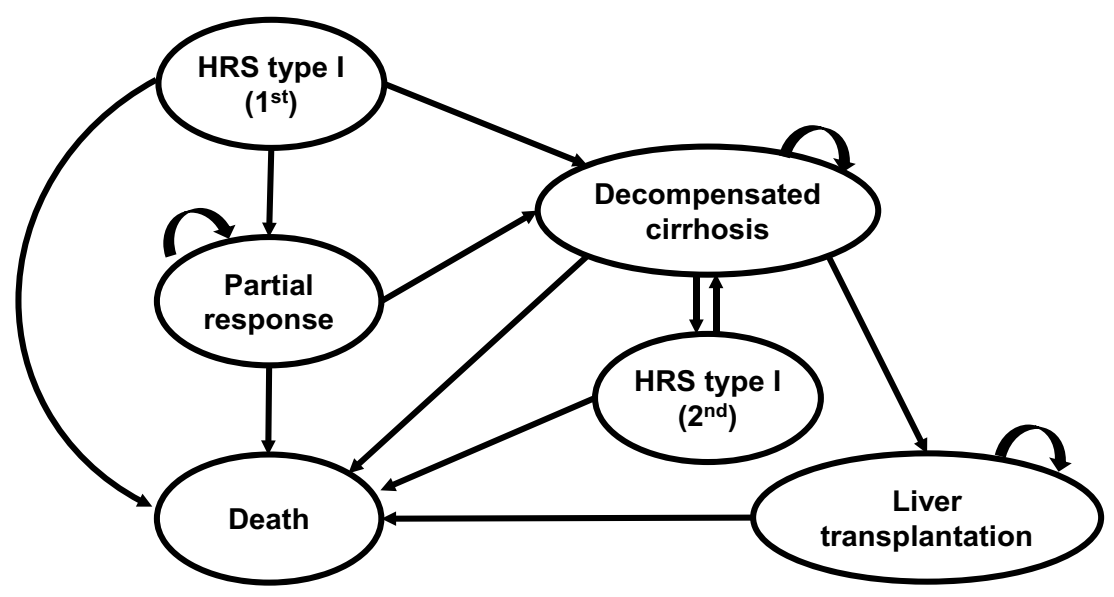

Figure I Schematic diagram of the Markov model representing the clinical progression type I hepatorenal syndrome (type I HRS). Notes: The arrows represent the transition from a health state to another health state or the same health state in the next cycle. Abbreviation: HRS, type I hepatorenal syndrome.

this Markov chain. The model was constructed and analyzed using Microsoft Excel.

The model assumed that there were no other complications apart from type $1 \mathrm{HRS}$ in these patients and type 1 HRS relapse could occur only once regardless of the given treatments. Additionally, the patients would be in the partial response not exceeding 90 days, then they would proceed to either death or decompensated cirrhosis with a complete HRS reversal state.

\section{Interventions and Comparator}

The interventions of interest were therapies with available vasoconstrictor drugs in Thailand, which were $\mathrm{T}+\mathrm{A}$ and $\mathrm{N}$ $+\mathrm{A}$. The comparator was BSC, as there is no specific treatment for type 1 HRS in the current situation. Albumin was administered in combination with terlipressin or noradrenaline and it was assumed that $50 \mathrm{~g}$ of albumin was given for one day, followed by $40 \mathrm{~g}$ of albumin per day until terlipressin or noradrenaline was discontinued.

\section{Model Parameters}

The four main groups of the model input parameters were transition probabilities, treatment efficacy, costs, and utilities (Table 1).

\section{Transition Probabilities and Treatment Efficacy}

The transition probabilities, the prevalence of ischemic events, and the relative risk (RR) in the vasoconstrictor therapies $(\mathrm{T}+\mathrm{A}$ and $\mathrm{N}+\mathrm{A})$ compared to $\mathrm{BSC}$ for the HRS reversal, mortality, ischemic events (eg, ischemic cardiac event, intestinal ischemia, peripheral vascular ischemia) from the 1st HRS, and HRS relapse were synthesized by network meta-analysis (NMA). This NMA included randomized-controlled trials (RCT) that were published until 2020 and were included in the existing metaanalyses $^{14,18,19}$ (Table S2, Table S3, and Table S4, in Supplementary Materials). Due to limited evidence, the 2nd occurrence of type 1 HRS was assumed to be fully recovered with the equivalent probability of HRS reversal from the first type $1 \mathrm{HRS}$. It was noted that ischemic events are important serious adverse events of both terlipressin and noradrenaline. We used relative risk of ischemic events of these vasoconstrictors compared to BSC for estimating patients suffering from this safe outcome after receiving these treatments.

The probabilities of death from decompensated cirrhosis and liver transplantation were obtained from literature $^{20,21}$ and they were integrated with age-specific all-cause mortality derived from the Thai population's life table data based on the report of Burden of Disease Research Program Thailand (BOD Thailand) B.E. 2556.

The mortality rate among $\mathrm{T}+\mathrm{A}$-treated patients who were partial responders was estimated from the REVERSE Study of Boyer et al. ${ }^{22}$ We assumed the same mortality rate among partial responders in the $\mathrm{N}+\mathrm{A}$ group. In the base-case, we assumed that $10 \%$ of decompensated cirrhosis patients underwent LT.

\section{Costs}

Direct medical costs included the drug costs retrieved from the reference price database of the Drugs and Medical Supplies Information Centre and costs of healthcare services and treatment in intensive care unit (ICU) obtained from the Standard Cost Lists for Health Economic 
Table I Input Model Parameters in the Base-Case Analysis

\begin{tabular}{|c|c|c|c|c|c|}
\hline \multicolumn{2}{|l|}{ Parameters } & Distribution & Mean & SE & Source \\
\hline \multicolumn{6}{|l|}{ Transition Probability } \\
\hline From & To & & & & \\
\hline The Ist HRS ${ }^{\dagger}$ & Dcom (HRS reversal) & Beta & 0.120 & 0.023 & Meta-analysis \\
\hline The Ist HRS & Death & Beta & 0.270 & 0.038 & Meta-analysis \\
\hline Dcom & 2nd HRS (HRS relapse) & Beta & 0.010 & 0.008 & Meta-analysis \\
\hline 2nd HRS (HRS relapse) & Death & Beta & 0.880 & N/A & Calculated $^{\dagger}$ \\
\hline Dcom & LT & Beta & 0.100 & 0.038 & Assumed \\
\hline LT & Death Year 0 & Beta & 0.000 & N/A & Calculated from \\
\hline LT & Death Year I & Beta & 0.100 & N/A & a study of \\
\hline LT & Death Year 2 & Beta & 0.028 & $\mathrm{~N} / \mathrm{A}$ & Pachanee et $\mathrm{al}^{21}$ \\
\hline LT & Death Year 3 & Beta & 0.029 & $\mathrm{~N} / \mathrm{A}$ & \\
\hline LT & Death Year 4 & Beta & 0.029 & $\mathrm{~N} / \mathrm{A}$ & \\
\hline LT & Death Year 5 & Beta & 0.030 & N/A & \\
\hline LT & Death Year 10 & Beta & 0.028 & N/A & \\
\hline LT & Death Year 15 & Beta & 0.015 & N/A & \\
\hline LT & Death Year 20 & Beta & 0.016 & N/A & \\
\hline LT & Death Year 30 & Beta & 0.020 & N/A & \\
\hline Dcom & Death & Beta & 0.012 & 0.009 & {$[28]$} \\
\hline \multicolumn{6}{|c|}{ Adverse Drug Events of Treatment: Ischemic Events } \\
\hline \multirow{3}{*}{\multicolumn{2}{|c|}{$\begin{array}{l}\text { RR of ischemic events (Terlipressin) } \\
\text { RR of ischemic events (Noradrenaline) } \\
\text { Prevalence of ischemic events (BSC) }\end{array}$}} & lognormal & 3.25 & 0.411 & Meta-analysis \\
\hline & & lognormal & 4.47 & 0.712 & Meta-analysis \\
\hline & & Beta & 0.02 & 0.013 & Meta-analysis \\
\hline \multicolumn{6}{|l|}{ Efficacy of Treatment } \\
\hline \multirow{4}{*}{\multicolumn{2}{|c|}{$\begin{array}{l}R R \text { of HRS reversal of } T+A \\
R R \text { of HRS reversal of } N+A \\
R R \text { of HRS death of } T+A \\
R R \text { of HRS death of } N+A\end{array}$}} & lognormal & 2.66 & 0.237 & Meta-analysis \\
\hline & & lognormal & 2.31 & 0.278 & Meta-analysis \\
\hline & & lognormal & 0.59 & 0.283 & Meta-analysis \\
\hline & & lognormal & 0.70 & 0.355 & Meta-analysis \\
\hline \multicolumn{6}{|l|}{ Liver Transplantation } \\
\hline \multicolumn{2}{|c|}{ Annual probability of $L T$ among Dcom patients } & Beta & 0.10 & 0.038 & {$[2 ।]$} \\
\hline \multicolumn{6}{|l|}{ Direct Medical Cost } \\
\hline \multicolumn{6}{|l|}{ Cost of Medications } \\
\hline \multirow{3}{*}{\multicolumn{2}{|c|}{$\begin{array}{l}\text { Cost of terlipressin per I vial (I mg/vial I,926 THB) } \\
\text { (THB) } \\
\text { Cost of noradrenaline per I mg (average price/amp Img/ } \\
\mathrm{mL} 4 \mathrm{~mL} \text { ) (THB) } \\
\text { Cost of albumin per } 10 \text { grams (average price of albumin } \\
20 \% 50 \mathrm{~mL} / \mathrm{vial})(\mathrm{THB})\end{array}$}} & Gamma & 1,926 & 1,926 & [29] \\
\hline & & Gamma & 35 & 35 & {$[30]$} \\
\hline & & Gamma & 1,245 & 1,245 & {$[3 \mid]$} \\
\hline \multicolumn{6}{|c|}{ Cost of Drug Administration } \\
\hline \multicolumn{2}{|c|}{ Cost of ICU THB/day for noradrenaline treatment (THB) } & Gamma & 5,490 & 5,490 & [32] \\
\hline \multicolumn{6}{|l|}{ Cost of Treatment } \\
\hline \multirow{3}{*}{\multicolumn{2}{|c|}{$\begin{array}{l}\text { HRS treatment cost per I admission (THB) }{ }^{\ddagger} \\
\text { Dcom treatment cost per cycle (THB) } \\
\text { Ischemic events treatment cost per I admission (THB) }\end{array}$}} & Gamma & 59,828 & 180 & Primary data from ${ }^{6}$ \\
\hline & & Gamma & 6,115 & 6,115 & {$[25]$} \\
\hline & & Gamma & 45,759 & 45,759 & {$[24]$} \\
\hline
\end{tabular}

(Continued) 
Table I (Continued).

\begin{tabular}{|c|c|c|c|c|}
\hline Parameters & Distribution & Mean & SE & Source \\
\hline \multicolumn{5}{|l|}{ Cost of LT (Excludes Treatment Cost for Complications) } \\
\hline $\begin{array}{l}\text { Patients with low risk and receive cyclosporine and } \\
\text { mycophenolate (THB) }\end{array}$ & Gamma & 520,000 & 520,000 & $\begin{array}{l}\text { The Royal } \\
\text { Government }\end{array}$ \\
\hline $\begin{array}{l}\text { Patients with low risk and receive tacrolimus and } \\
\text { mycophenolate (THB) }\end{array}$ & Gamma & 540,000 & 540,000 & $\begin{array}{l}\text { Gazette: The } \\
\text { announcements of }\end{array}$ \\
\hline $\begin{array}{l}\text { Patients with high risk and receive basiliximab, } \\
\text { cyclosporine, and mycophenolate (THB) }\end{array}$ & Gamma & 660,000 & 660,000 & $\begin{array}{l}\text { the medical } \\
\text { committees }\end{array}$ \\
\hline $\begin{array}{l}\text { Patients with high risk and receive basiliximab, tacrolimus, } \\
\text { and mycophenolate (THB) }\end{array}$ & Gamma & 680,000 & 680,000 & $\begin{array}{l}\text { according to the } \\
\text { Social Security Act }\end{array}$ \\
\hline $\begin{array}{l}\text { Monthly cost of immunosuppressant after LT: month I-6 } \\
\text { in year (THB) }\end{array}$ & Gamma & 30,000 & 30,000 & B.E. 2533 \\
\hline $\begin{array}{l}\text { Monthly cost of immunosuppressant after LT: month 7-12 } \\
\text { in year (THB) }\end{array}$ & Gamma & 25,000 & 25,000 & \\
\hline $\begin{array}{l}\text { Monthly cost of immunosuppressant after LT in year } 2 \\
\text { (THB) }\end{array}$ & Gamma & 20,000 & 20,000 & \\
\hline $\begin{array}{l}\text { Monthly cost of immunosuppressant after LT; year:3 } \\
\text { onward (THB) }\end{array}$ & Gamma & 15,000 & 15,000 & \\
\hline \multicolumn{5}{|l|}{ Direct Non-Medical Cost ${ }^{\top}$} \\
\hline Travel cost (THB/day) & Gamma & 155 & 155 & [33] \\
\hline Food cost (THB/day) & Gamma & 57 & 57 & [33] \\
\hline Income per capita per year (THB) & Gamma & 205,081 & 205,081 & $\begin{array}{l}\text { National Statistical } \\
\text { Office (2005- } \\
2014)\end{array}$ \\
\hline Time spent in OPD per day (minutes) & Normal & 361 & 8 & [33] \\
\hline Average LOS for type I HRS (days) & Gamma & 7 & 7 & $\begin{array}{l}\text { Assumed equal to } \\
\text { duration of } \\
\text { treatment }\end{array}$ \\
\hline Average LOS for LT (days) & Gamma & 14 & 14 & Assumed \\
\hline \multicolumn{5}{|l|}{ Utilities } \\
\hline Type I HRS & Beta & 0.45 & 0.25 & [26] \\
\hline Decompensated cirrhosis & Beta & 0.74 & 0.2 & {$[26]$} \\
\hline Early posttransplantation (operation) & Beta & 0.765 & 0.0187 & {$[27]$} \\
\hline Intermediate posttransplantation (year I-3) & Beta & 0.832 & 0.0163 & [27] \\
\hline Late posttransplantation (year 4 onwards) & Beta & 0.817 & 0.0203 & [27] \\
\hline
\end{tabular}

Notes: Italicized-bold text represents the parameter categories and italicized text represents subgroups of the parameter categories. ${ }^{\dagger}$ Similar to the transition from the Ist HRS to Dcom, the probability of reversal from the 2nd occurrence of type I HRS (placebo) was assumed to be equal to the probability of HRS reversal after the Ist occurrence of type I HRS (placebo). Additionally, the probability of death from the 2nd HRS (HRS relapse) was calculated from I minus the probability of reversal from the 2nd occurrence of type I HRS (placebo). ${ }^{\ddagger}$ The HRS treatment cost per I admission covered inpatient service, treatment monitoring, and other supportive treatments, but it excluded costs of T+A and N+A treatment. "Regarding direct non-medical cost, productivity loss of a caregiver during hospitalization due to HRS and liver transplantation were estimated using 7 days and 14 days of the length of stay, respectively. A monthly outpatient visits of the patient during treatment with immunosuppressive drugs was applied for calculating the productivity loss of a caregiver.

Abbreviations: BSC, best supportive care; Dcom, decompensated cirrhosis; HRS, type I hepatorenal syndrome; ICT, intensive care unit; LOS, length of stay; LT, liver transplantation; mg, milligram; $\mathrm{mL}$, milliliter; N/A, not applicable; N+A, noradrenaline plus albumin; OPD, outpatient department; RR, relative risk; SE, standard error; $T+A$, terlipressin plus albumin; THB, Thai baht.

Evaluation in Thailand and reimbursement guideline for public hospitals in Thailand. The cost of hospitalization due to HRS (ICD-10 K76.7) was estimated from the charge per HRS admission in tertiary and teaching hospitals during 2009-2013 derived from the National Health
Security Office's database. For the base-case scenario, 1-mg terlipressin was administered every 6 hours for 7 days, while 0.5-mg noradrenaline was given every hour for 7 days. Both treatments were combined with 50-mg albumin on day one, followed by 40-mg albumin per day for 6 
days. These regimens were validated by experts and in line with the RCT conducted by Sharma et al. ${ }^{23}$ Regarding the variation of dose and duration of the treatments in a realworld setting, we performed sensitivity analyses using the five scenarios, which had an impact on the difference of the treatment costs (Table S1 in Supplementary Materials). However, the treatment efficacies of these scenarios were assumed to be equivalent due to scarcity of evidence. Cost of management for the adverse events for any interventions derived from a study determining treatment cost of ischemic cardiac events in Thai setting. ${ }^{24}$ We assumed that the treatment with either $\mathrm{T}+\mathrm{A}$ or $\mathrm{N}+\mathrm{A}$ was discontinued during the ischemic events. The cost of an outpatient visit for patients with decompensated cirrhosis was obtained from literature. ${ }^{25}$ Lengths of stay (LOS) for HRS were assumed to be equal to the duration of $\mathrm{T}+\mathrm{A}, \mathrm{N}+\mathrm{A}$, or placebo, whereas LOS for LT was set at 14 days. The costs related to LT covered surgery, hospital services, laboratory testing, and immunosuppressants. As the reimbursements under the Social Security Act B.E. 2533 for LT with and without complications were different $(680,000$ THB vs 520,000 THB), we assumed that the complication associated with LT could occur in $30 \%$ of the patients. It was assumed that patients did not undergo transjugular intrahepatic portosystemic shunt (TIPS) or dialysis. Besides, we excluded treatment costs for the etiology of HRS such as spontaneous bacterial peritonitis and hepatic encephalopathy.

Direct non-medical costs comprised costs of food, transportation, accommodation, modification, productivity loss of caregivers. Indirect costs were omitted to avoid double counting in the CUA according to the recommendation from the Thai Health Technology Assessment guidelines. ${ }^{16}$ All incurred costs were converted to 2019 values using the consumer price index.

\section{Utilities}

The utility weight for decompensated cirrhotic patients who were completely cured of type 1 HRS was obtained from a published study. ${ }^{20}$ This study performed the systematic review and pooled utility weighted that were obtained from the included studies. ${ }^{20}$ The prevalence of type 1 HRS was rare and the patients with type 1 HRS are generally very sick or cannot provide their quality of life (QoL) data. Therefore, utility weights for the 1st and 2nd type $1 \mathrm{HRS}$ and partial responders were assumed to be equal to spontaneous bacterial peritonitis, which was obtained using the time trade-off method $(\mathrm{n}=114){ }^{26}$ The utility values applied for post- transplantation patients were divided into early posttransplant (the first year), intermediate post-transplant (year 13 ), and late post-transplant (year 4 onwards). ${ }^{27}$

\section{Result Presentation}

Total cost, life-years (LYs), and quality-adjusted life-years (QALYs) for individual treatments were reported. The incremental cost-effectiveness ratios (ICER) per QALY gained in Thai Baht (THB) for $\mathrm{T}+\mathrm{A}$ and $\mathrm{N}+\mathrm{A}$ treatments were calculated by an incremental cost divided by incremental LYs or QALYs. The Thai societal willingness-topay (WTP) of 160,000 THB per QALY gained was adopted as the cost-effectiveness threshold.

\section{Uncertainty Analyses}

\section{Parameter Uncertainty}

To assess the uncertainties of each parameter, a one-way sensitivity analysis of $\mathrm{T}+\mathrm{A}$ and $\mathrm{N}+\mathrm{A}$ was performed and presented the results using tornado diagrams. In this analysis, the $95 \%$ CI values were used for the general parameters. The increase and decrease for $10 \%$ of mean values were applied for RR, utilities, and cost of LT. The discount rates for costs and outcomes varied from $0 \%$ to $6 \%$. Durations of terlipressin or noradrenaline administration, as well as the length of stay due to type $1 \mathrm{HRS}$, were assumed to be 1 to 14 days. We assumed that $5 \%$ to $20 \%$ of the patients undergo LT and the length of stay for the LT ranged from 7 to 21 days. The uncertainty of all parameters was evaluated simultaneously in probabilistic sensitivity analyses (PSA). The Monte Carlo simulation was run for 1000 times and the results of PSA were shown as cost-effectiveness acceptability curves (CEAC) and cost-effectiveness plane.

\section{Scenario Analysis}

As direct medical costs might be substantially sensitive to costs of the drug treatment. The analyses on additional four scenarios with different doses and length of treatment of the $\mathrm{T}+\mathrm{A}$ and $\mathrm{N}+\mathrm{A}$ treatments (Table S1 in Supplementary Materials) were conducted. However, the drug efficacies and safety were assumed to be equivalent across all scenarios due to limited evidence. The situation of administering noradrenaline outside ICU was also examined.

Stakeholders including representatives from the national payer agencies, policymakers from the NLEM and the health economic working group, and gastroenterologists were involved in the meetings of proposal development and preliminary result presentation of this study. This process ensured the appropriateness of the 
comparators, model structure, parameters, and assumptions in concordance with the current clinical practice in Thailand.

\section{Results}

\section{Base-Case Analysis}

The cost-utility analysis results were demonstrated (Table 2). From a societal perspective, patients receiving BSC had the lowest cost $(603,865 \mathrm{THB})$, while those receiving $\mathrm{T}+\mathrm{A}$ had the highest cost $(848,325 \mathrm{THB})$, but they also achieved the highest total outcomes with 2.82 LYs and 2.27 QALYs compared to the other treatments. Compared to BSC, $\mathrm{T}+\mathrm{A}$ had the ICER values under the societal and payer perspectives lower than the $\mathrm{N}+\mathrm{A}$ treatment $(377,566$ and 366,871 THB per QALY gained, respectively).

Regarding the lifetime costs described by the main health states, the cost drivers included LT, followed by treatment for HRS and treatment for decompensated cirrhosis in both interventions (Figure S1-S2 in Supplementary Materials). In terms of cost components, the lifetime cost of terlipressin was much higher than the cost of noradrenaline. Although the cost of ICU for administering noradrenaline was high, the overall cost of HRS treatment using $\mathrm{T}+\mathrm{A}$ remained higher than $\mathrm{N}+\mathrm{A}$ treatment (Figure S2 in Supplementary Materials).

\section{Uncertainty Analyses \\ Parameter Uncertainty}

The results of one-way sensitivity analysis of $\mathrm{T}+\mathrm{A}$ and $\mathrm{N}+\mathrm{A}$ were presented as two tornado diagrams in Figure 2. For patients receiving $\mathrm{T}+\mathrm{A}$, the ICER was most sensitive to variations in monthly treatment cost after LT from year 3 onward, cost of terlipressin, cost of albumin, cost of treating decompensated cirrhosis, and the probability of transitioning from decompensated cirrhosis to death. In addition, the ICER of $\mathrm{N}+\mathrm{A}$ was most heavily influenced by the monthly treatment cost after LT from year 3 onward, duration of noradrenaline administration, cost of albumin, cost of ICU per day, and RR of type 1 HRS reversal.

The PSA on all parameters including cost drivers, ie, LT, treatment for HRS and treatment for decompensated cirrhosis performed based on a societal perspective revealed the robustness of the base-case results. The CEAC (Figure 3) illustrates that BSC had the highest probability of being cost-effective at $69 \%$, followed by $\mathrm{N}$ $+\mathrm{A}$ and $\mathrm{T}+\mathrm{A}$ at $20 \%$ and $11 \%$, respectively. When the willingness to pay threshold was increased to approximately 280,000 THB per QALY gained and 360,000 THB per $\mathrm{QALY}$ gained, $\mathrm{T}+\mathrm{A}$ would have a higher probability of being more cost-effective than $\mathrm{N}+\mathrm{A}$ and $\mathrm{BSC}$, respectively. The cost-effectiveness plane from 1000 iterations for $\mathrm{T}+\mathrm{A}$ and $\mathrm{N}+\mathrm{A}$ compared with $\mathrm{BSC}$ is shown in $\underline{\text { Figure S3 in Supplementary Materials. }}$

\section{Scenario Analysis}

When varying dosage regimens of the vasoconstrictors, the total costs of $\mathrm{T}+\mathrm{A}$ and $\mathrm{N}+\mathrm{A}$ lied between 848,325 (basecase) and 1,177,657 THB (scenario 4: maximum frequency for 14 days) and between 779,973 (base-case) and 915,424 THB (scenario 4), respectively. As the result, the ICER values of $\mathrm{T}+\mathrm{A}$ and $\mathrm{N}+\mathrm{A}$ ranged from 377,566

Table 2 Total Costs, Effectiveness, and ICER from the Base-Case Analysis

\begin{tabular}{|c|c|c|c|c|c|c|c|c|}
\hline \multirow[t]{2}{*}{ Treatment } & \multirow[t]{2}{*}{ Total Cost (THB) } & \multicolumn{2}{|c|}{ Total Effectiveness } & \multirow[t]{2}{*}{$\begin{array}{l}\text { Incremental } \\
\text { Cost (THB) }\end{array}$} & \multicolumn{2}{|c|}{$\begin{array}{l}\text { Incremental } \\
\text { Effectiveness }\end{array}$} & \multicolumn{2}{|l|}{ ICER } \\
\hline & & LY & QALY & & LY & QALY & Per LY & Per QALY \\
\hline \multicolumn{9}{|l|}{ Societal } \\
\hline \multicolumn{9}{|l|}{ Perspective } \\
\hline BSC & $603,865(650,257)$ & $2.04(2.36)$ & $1.62(1.88)$ & & & & & \\
\hline$T+A^{*}$ & $848,325(919,782)$ & $2.82(3.35)$ & $2.27(2.69)$ & $244,460(269,526)$ & $0.78(0.98)$ & $0.65(0.8 I)$ & $3 \mid 2,528(274,901)$ & $377,566(333,708)$ \\
\hline$N+A^{*}$ & $779,973(846,298)$ & $2.55(3.01)$ & $2.05(2.42)$ & $176,109(196,041)$ & $0.51(0.65)$ & $0.43(0.53)$ & $343,333(303,331)$ & $4 \mid 2,979(366,904)$ \\
\hline \multicolumn{9}{|l|}{ Payer } \\
\hline BSC & $565,396(668,626)$ & $2.04(2.33)$ & $1.62(1.86)$ & & & & & \\
\hline$T+A^{*}$ & $802,93 \mathrm{I}(957,843)$ & $2.82(3.31)$ & $2.27(2.67)$ & $237,535(289,216)$ & $0.78(0.98)$ & $0.65(0.81)$ & $303,675(296,425)$ & $366,871(358,678)$ \\
\hline$N+A^{*}$ & $737,527(867,270)$ & $2.55(2.96)$ & $2.05(2.38)$ & $172,132(198,643)$ & $0.51(0.63)$ & $0.43(0.52)$ & $335,579(316,936)$ & $403,652(383,990)$ \\
\hline
\end{tabular}

Notes: Italicized text indicating the perspective of analysis. The values in brackets were results from the probabilistic model. *In base-case, I mg of terlipressin was given every 6 hours for 7 days, $0.5 \mathrm{mg}$ of noradrenaline was given every hour for 7 days in the intensive care unit. Albumin was given for both groups for 7 days ( $50 \mathrm{~g}$ of albumin on day I followed by $40 \mathrm{~g}$ of albumin per day).

Abbreviations: BSC, best supportive care; ICER, incremental cost-effectiveness ratio; LY, life-year; N+A, noradrenaline plus albumin; $Q A L Y$, quality-adjusted life-year; $T+A$, terlipressin plus albumin; THB, Thai baht. 
A

Tornado diagram

A Terlipressin plus albumin vs. Best supportive care

$-40 \%-30 \%-20 \%-10 \% \quad 0 \% \quad 10 \% \quad 20 \% \quad 30 \% \quad 40 \% \quad 50 \% \quad 60 \% \quad 70 \% \quad 80 \% \quad 90 \% 100 \% 110 \%$

Monthly cost of treatment after liver transplantation; year 3 onward

Cost of terlipressin per 1 vial

Cost of albumin per $10 \mathrm{~g}$

Cost of treatment for decompensated cirrhosis per cycle

Transitional probability: decompensated cirrhosis to death

Relative risk of HRS reversal $(T+A)$

Transitional probability: HRS (1st) to reversal (BSC)

Duration of terlipressin treatment (days)

Annual probability of undergoing liver transplantation among decompensated cirrhosis patients

Lifetime cost related to liver transplantation

\section{$-37 \%$}

$$
-25 \%
$$

$65 \%$

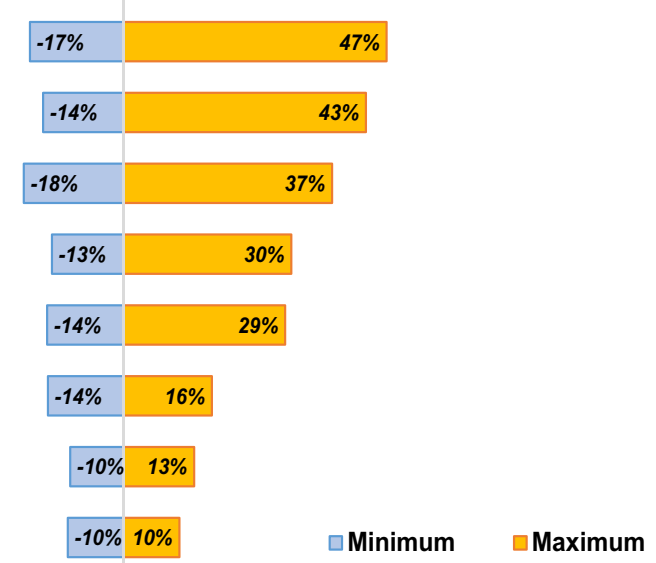

B

Noradrenaline plus albumin vs. Best supportive care

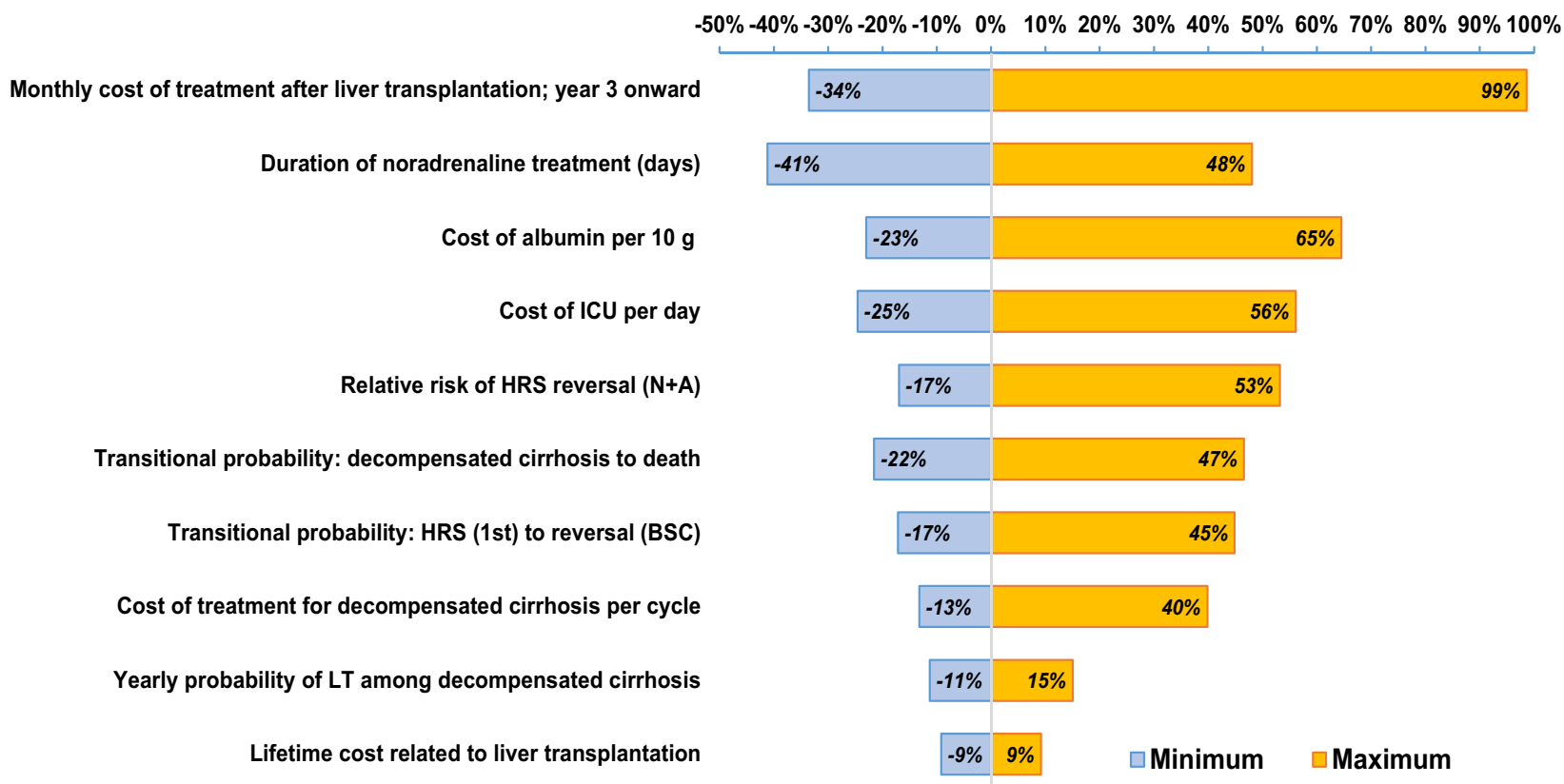

Remarks: The patients receive a vasoconstrictor therapy and liver transplantation.

Figure 2 A tornado diagram showing the percentages of change in the incremental QALYs from the base-case attributable to the change of each parameter: (A) Terlipressin plus albumin versus best supportive care and (B) Noradrenaline plus albumin versus best supportive care.

Abbreviations: BSC, best supportive care; g, gram; HRS, type I hepatorenal syndrome; ICER, incremental cost-effectiveness ratio; ICU, intensive care unit; LT, liver transplant; $N+A$, noradrenaline plus albumin; $T+A$, terlipressin plus albumin; $T H B$, Thai baht.

(base-case) to 861,080 (scenario 4) THB per QALY gained and 412,979 (base-case) to 692,451 (scenario 4) THB per QALY gained, respectively.
When $\mathrm{N}+\mathrm{A}$ was assumed to be given outside ICU, this intervention had the lowest total cost and ICER for all scenarios. Besides, scenario 1 (base-case) and scenario 4 


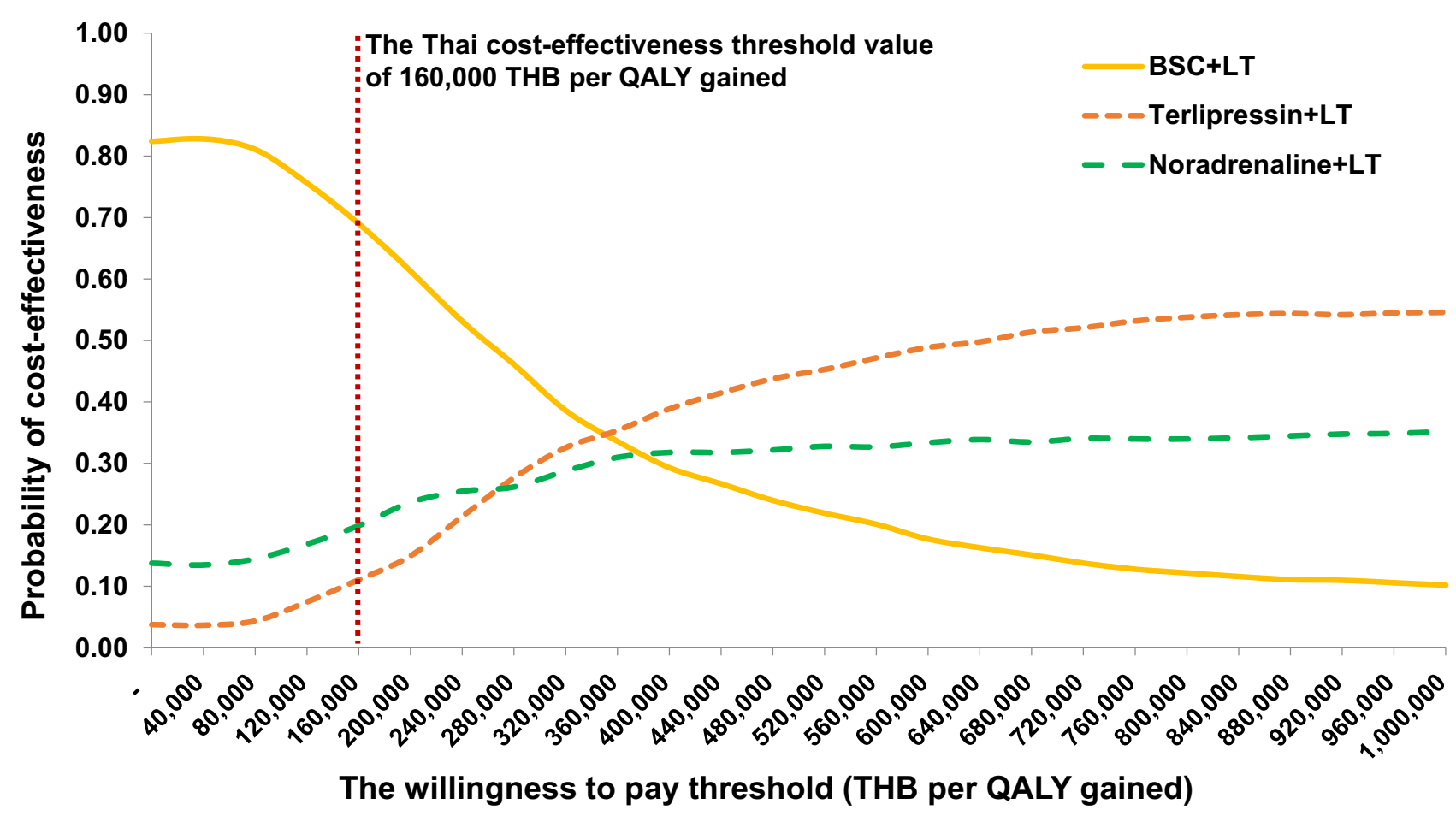

Figure 3 Cost-effectiveness acceptability curves comparing the probabilities of being cost-effective at different willingness-to-pay of terlipressin plus albumin, noradrenaline plus albumin, and best supportive care in base-case scenario.

Note: Terlipressin and noradrenaline were given in combination with albumin.

Abbreviations: BSC, best supportive care; LT, liver transplant; QALY, quality-adjusted life-year; THB, Thai baht.

(the drug was given at maximum frequency and duration) produced the lowest and highest ICER for all interventions. The results from scenario analysis under a societal perspective are shown in Table 3.

\section{Discussion}

This is the first study to examine the cost-effectiveness of all available treatments for type 1 HRS in Thailand. As the ultimate benefit of the vasoconstrictor therapies is to extend the lives of patients with decompensated cirrhosis until having a chance to receive the curative LT, our Markov model incorporated the LT as a health state, which has never been considered in all existing economic evaluation studies. In addition, our study also applied the pooled estimates of treatment effects obtained from our network meta-analysis of the most recent RCTs. Concerning the different perspectives of the analysis, the total cost of the payer perspective was lower than the total cost of the societal perspective, which includes both direct medical costs and direct non-medical costs. As the health benefit of the treatments under those perspectives was the same, the ICER derived from the payer perspective was lower than the societal perspective. Although both $\mathrm{T}+\mathrm{A}$ and $\mathrm{N}+\mathrm{A}$ were associated with higher effectiveness in terms of LYs and QALYs, their lifetime costs were considerably high. Therefore, $\mathrm{T}+\mathrm{A}$ and $\mathrm{N}+\mathrm{A}$ administered inside and outside

ICU would not be cost-effective compared to BSC under the WTP threshold at 160,000 THB per QALY gained. The major cost-driven factors were LT-related expenses (eg, surgery and immunosuppressants) followed by the drug cost for treating HRS. This is in line with the study of Pachanee et al suggesting that LT led to a substantial increase in LY and QoL but its high operation cost as well as costly immunosuppressants resulted in less cost-effective of $\mathrm{LT}^{21}$

Compared to three existing economic evaluations that assessed the cost-effectiveness of vasoconstrictor therapies and albumin for type $1 \mathrm{HRS},{ }^{15,34,35}$ none of them considered the cost and outcome related to LT. In addition, study design, target population, perspective, costs of treatments among these studies were different from our study. Therefore, the findings from this study were relatively different from these studies indicating that the total cost of albumin and terlipressin was slightly lower than that of albumin and noradrenaline, but the survival rates and QALY of albumin and 
Table 3 Total Costs, Effectiveness, and ICER from Scenario Analysis Under a Societal Perspective

\begin{tabular}{|c|c|c|c|c|c|c|}
\hline Scenario & Intervention & $\begin{array}{l}\text { Total Cost } \\
\text { (THB) }\end{array}$ & $\begin{array}{l}\text { Total } \\
\text { QALYs }\end{array}$ & $\begin{array}{c}\text { Incremental Cost } \\
\text { (THB) }\end{array}$ & $\begin{array}{c}\text { Incremental } \\
\text { QALYs }\end{array}$ & $\begin{array}{c}\text { ICER (THB/QALY } \\
\text { Gained) }\end{array}$ \\
\hline \multirow[t]{4}{*}{ I (Base -case) } & BSC & 603,865 & 1.62 & & & \\
\hline & $\mathrm{T}+\mathrm{A}$ & 848,325 & 2.27 & 244,460 & 0.65 & 377,566 \\
\hline & $N+A$ & 779,973 & 2.05 & 176,109 & 0.43 & $4 \mid 2,979$ \\
\hline & $\mathrm{N}+\mathrm{A}($ non-ICU) & 735,618 & 2.05 & $|3|, 753$ & 0.43 & 308,964 \\
\hline \multirow[t]{4}{*}{2} & BSC & 620,139 & 1.62 & & & \\
\hline & $\mathrm{T}+\mathrm{A}$ & 966,196 & 2.27 & 346,057 & 0.65 & $534,48 I$ \\
\hline & $N+A$ & 882,294 & 2.05 & 262,155 & 0.43 & 614,760 \\
\hline & $\mathrm{N}+\mathrm{A}($ non-ICU) & 793,583 & 2.05 & 173,444 & 0.43 & 406,731 \\
\hline \multirow[t]{4}{*}{3} & BSC & 620,139 & 1.62 & & & \\
\hline & $\mathrm{T}+\mathrm{A}$ & $1,065,178$ & 2.27 & 445,039 & 0.65 & 687,357 \\
\hline & $N+A$ & 895,792 & 2.05 & 275,653 & 0.43 & 646,412 \\
\hline & $\mathrm{N}+\mathrm{A}$ (non-ICU) & 807,081 & 2.05 & 186,942 & 0.43 & 438,381 \\
\hline \multirow[t]{4}{*}{4} & BSC & 620,139 & 1.62 & & & \\
\hline & $T+A$ & I, I77,657 & 2.27 & 557,518 & 0.65 & $86 I, 080$ \\
\hline & $N+A$ & 915,424 & 2.05 & 295,285 & 0.43 & 692,451 \\
\hline & $\mathrm{N}+\mathrm{A}($ non-ICU) & $826,7 \mid 4$ & 2.05 & 206,575 & 0.43 & 484,422 \\
\hline \multirow[t]{4}{*}{5} & BSC & 606,608 & 1.62 & & & \\
\hline & $\mathrm{T}+\mathrm{A}$ & 866,722 & 2.27 & 260,114 & 0.65 & $40 I, 744$ \\
\hline & $N+A$ & 802,736 & 2.05 & 196,128 & 0.43 & 459,925 \\
\hline & $\mathrm{N}+\mathrm{A}($ non-ICU) & 749,130 & 2.05 & 142,522 & 0.43 & 334,216 \\
\hline
\end{tabular}

Notes: BSC is a Reference. N+A (non-ICU) is a scenario of administering noradrenaline plus albumin outside an intensive care unit. Scenario I: Terlipressin I mg every 6 hours for 7 days vs Noradrenaline $0.5 \mathrm{mg}$ every hour for 7 days. Scenario 2: Terlipressin $1 \mathrm{mg}$ every 6 hours for 14 days vs Noradrenaline 0.5 mg every hour for 14 days. Scenario 3: Terlipressin I mg every 6 hours for 3 days, followed by $2 \mathrm{mg}$ every 6 hours for II days vs Noradrenaline $0.5 \mathrm{mg} /$ hour for 4 hours, then increasing the dose for $0.5 \mathrm{mg}$ /hour at four-hour intervals up to a maximum of $1.5 \mathrm{mg} /$ hour and continuing this dose for 13 days. Scenario 4 : Terlipressin $1 \mathrm{mg}$ every 4 hours for 3 days, followed by $2 \mathrm{mg}$ every 4 hours for II days vs Noradrenaline $0.5 \mathrm{mg} /$ hour for 4 hours, then increasing the dose for $0.5 \mathrm{mg} /$ hour at four-hour intervals up to a maximum of $3 \mathrm{mg} / \mathrm{hour}$ and continuing this dose for 13 days. Scenario 5: Terlipressin $3.92 \mathrm{mg}$ (median dose) for 8.18 days (median treatment duration) vs Noradrenaline $17.76 \mathrm{mg}$ (median dose) for 8.46 days (median treatment duration). Albumin was given for both groups with $50 \mathrm{~g}$ of on day I followed by $40 \mathrm{~g}$ per day. It was administered for $\mathrm{I} 4$ days for the scenario 2 to 3 and 8 days for the scenario 4 (Table SI in Supplementary Materials).

Abbreviations: BSC, best supportive care; ICER, incremental cost-effectiveness ratio; ICU, intensive care unit; $N+A$, noradrenaline plus albumin; QALY, quality-adjusted life-year; $T+A$, terlipressin plus albumin; THB, Thai baht.

terlipressin were the highest. According to the study of Mattos et al, the results from cost-minimization analysis highlighted the benefit of $\mathrm{T}+\mathrm{A}$ over $\mathrm{N}+\mathrm{A}$ in terms of cost and ICU bed saving, while no difference in the 30-day survival between treatment with terlipressin or noradrenaline (RR, 1.04; 95\% CI, 0.84-1.30) was found. ${ }^{15}$ Moreover, the study by Runken et al $^{35}$ conducted the cost-effectiveness of albumin plus vasoconstrictor compared to vasoconstrictor alone in the type $1 \mathrm{HRS}$ treatment among decompensated cirrhosis in Germany, Italy, and Spain using a decision tree economic model with a 3-month time horizon to capture both costs and outcomes during hospitalization of decompensated cirrhosis from the hospital perspective revealed that the combinations of albumin plus either terlipressin or noradrenaline (dominant therapy) were both less costly and more effective than the vasoconstrictor alone across the three countries.
The robustness of the results was confirmed by oneway sensitivity analysis and PSA that varied all parameters across the plausible ranges. The results from these analyses together with scenario analysis showed that $\mathrm{T}+\mathrm{A}$ and $\mathrm{N}+\mathrm{A}$ would not be cost-effective at the WTP threshold of 160,000 THB per QALY gained. BSC had the highest probability of being cost-effective, even though this option elicited a poorer health outcome. Although $\mathrm{T}+\mathrm{A}$ was the most efficacious treatment in all scenarios, the probability of being cost-effective was lower than $\mathrm{N}+\mathrm{A}$ due to its higher total cost, particularly resulted from a very high cost of terlipressin. Even though noradrenaline was much cheaper than terlipressin, the high cost of management in ICU had a substantial impact on the total treatment cost as well as ICER value.

Furthermore, the most influential factor of ICER change was the cost of immunosuppressive therapy after 
LT from year 3 onwards. Increasing dose and treatment duration of terlipressin and noradrenaline also had a considerable impact on the total costs and ICER values of $\mathrm{T}+\mathrm{A}$ and $\mathrm{N}+\mathrm{A}$. These increases in the total costs caused by the length of treatment might be associated with the cost of terlipressin and the cost of intensive care for noradrenaline administration.

Although $\mathrm{T}+\mathrm{A}$ and $\mathrm{N}+\mathrm{A}$ would not be cost-effective in Thai context, but these treatments could improve survival in patients with type 1 HRS on the waiting list for LT, which could potentially help save lives. Therefore, we estimated the budget impact of $\mathrm{T}+\mathrm{A}$ and $\mathrm{N}+\mathrm{A}$ for treating type $1 \mathrm{HRS}$ compared to BSC from the payer perspective using unpublished data from the study of Charatcharoenwitthaya et al (the average hospitalization with the type 1 HRS (ICD-10: K76.7) was 248 episodes per year). ${ }^{6}$ If we assumed that there were $90 \%$ of the patients eligible for these treatments and the coverage rate of the treatments was $50 \%$, there would be 110 cases receiving such treatments annually. For the first year, the total budgets required for $\mathrm{T}+\mathrm{A}, \mathrm{N}+\mathrm{A}$ in $\mathrm{ICU}$, and $\mathrm{N}+\mathrm{A}$ outside ICU were 16.8 million, 15.6 million, and 11.3 million THB. Compared with BSC (6.7 million THB), the additional budgets for these interventions were quite low (ranged from 4.6 million to 10.1 million THB) due to the low prevalence of the type 1 HRS.

At the moment, there is no treatment option for treating type 1 HRS in the NLEM and patients need to be responsible for all treatment expenses. These pharmacological interventions were life-saving therapies to prolong patients' lives while being on the waiting list for LT. Considering type 1 HRS as a rare condition, the total budget impacts for both $\mathrm{T}$ $+\mathrm{A}$ and $\mathrm{N}+\mathrm{A}$ were projected to be low. Therefore, our results suggested that $\mathrm{T}+\mathrm{A}$ and $\mathrm{N}+\mathrm{A}$ should be included in the NLEM due to low budget impact, even though these treatments would not be cost-effective. Generally, noradrenaline should be administered in ICU where it may be limited in some healthcare settings. Thus, $\mathrm{T}+\mathrm{A}$ treatment would be a more preferable option.

Moreover, it was noted that the supply of albumin and LT should be concerned if terlipressin and noradrenaline were included in the NLEM. In terms of albumin, its cost was high, and an adequate supply of albumin has been a problematic issue in Thailand. As both vasoconstrictors are needed to be used with albumin, the proper management of available albumin is required. Additionally, LT would effectively enhance the health benefit of $\mathrm{T}+\mathrm{A}$ and $\mathrm{N}+\mathrm{A}$. However, the scarcity of liver organ donation under opt-in consent remains an important problem. Although the number of liver donations has been increased in Thailand, the number of consented liver donors and patients on the waiting list who successfully underwent LT remains low. According to a report of the Thai Red Cross Organ Donation Centre, there was only $30 \%(78 / 257)$ and $40 \%(94 / 225)$ of patients on the waiting list who underwent LT with an average waiting time of 214 and 256 days in 2018 and 2019, respectively. Besides, patients aged 18 years and over who are beneficiaries of all health insurance schemes do not have to bear a very high cost of LT surgery, which was covered by health insurance agencies. Therefore, the inclusion of the type 1 HRS treatment into the NLEM should be considered, as this could enhance equity and the right to access the life-saving treatments. The price negotiation and seeking for potential generic drugs would be an essential mechanism to reduce the cost of the vasoconstrictor therapies plus albumin, immunosuppressive drugs, and antibiotics for LT patients in the future.

It was important to address the limitations in our studies. First, there was a lack of evidence supporting the efficacies and the safety of these drugs for certain health states. Moreover, most RCTs had small sample sizes due to the rare prevalence of type $1 \mathrm{HRS}$ and might affect the validity of the results. Thus, some parameters needed to be drawn from a single RCT. Second, the vasoconstrictor therapies were discontinued in patients who developed the ischemic events and there was a cost of management for the adverse events. We assumed that such adverse events had no impact on HRS reversal and mortality rate. This assumption was similar to a study of Boyer et $\mathrm{al}^{22}$ in which no death from ischemic events in the terlipressin-treated patients with type $1 \mathrm{HRS}$ was found. ${ }^{22}$ We also assumed the equal ischemic event rate and mortality from the interventions across different dosage regimens in the scenario analyses due to the limited evidence. The increasing dose and duration are likely to increase the rate and severity of these serious adverse events. Thus, these assumptions could lead to the cost underestimation. However, the robustness of our results was confirmed by extensive uncertainty analyses. Finally, we applied the utility weights $(0.45)$ obtained from the published literature $^{26}$ that collected data from patients with spontaneous bacterial peritonitis for the HRS health states due to the limited availability of the data. However, it should be concerned that patients with type 1 HRS have a worse prognosis than those with spontaneous bacterial peritonitis. According to the one-way sensitivity analysis, varying the utility values for patients with type 1 HRS from 0.36 to 0.54 resulted in changes in ICERs from $-0.2 \%$ to $0.2 \%$. 
Therefore, this parameter was likely to have a small impact on the results.

\section{Conclusion}

Systemic vasoconstrictor therapy combined with albumin has been considered as the first-line treatment for a life-threatening type 1 HRS. This comprehensive CUA focused on decompensated cirrhosis patients with type $1 \mathrm{HRS}$ who were eligible for LT. As a bridging therapy for LT, the vasoactive therapies plus albumin provided better health outcomes but remained costly and were not cost-effective compared to BSC. The cost of LT and drug cost for HRS treatment were significant key factors influencing changes in the ICER.

Although these life-saving treatments were costly and not cost-effective in the Thai context, the inclusion of either terlipressin and noradrenaline as well as LT along with immunosuppressive therapy for this rare condition causes low budget impacts and will prolong their lives as well as enhance equity among the national health insurance schemes in Thailand.

\section{Acknowledgments}

We are very grateful to Assoc. Prof. Dr. Tawesak Tanwandee, Prof. Dr. Sombat Treeprasertsuk, Asst. Prof. Dr. Chalermrat Bunchorntavakul, and other stakeholders for providing information and valuable suggestions during the expert meetings. We would like to thank Miss Waranya Rattanavipapong, MSc for technical support on the model construction.

\section{Author Contributions}

All authors made a significant contribution to the work reported, whether that is in the conception, study design, execution, acquisition of data, analysis and interpretation, or in all these areas; took part in drafting, revising or critically reviewing the article; gave final approval of the version to be published; have agreed on the journal to which the article has been submitted; and agree to be accountable for all aspects of the work.

\section{Funding}

This study was supported by the Thai Food and Drug Administration through the health economic working group under the Subcommittee for the development of the National List of Essential Medicines. The funder had a role in approving the study design but had no role in design, conduct of study, data collection, data analysis, decision to publish, preparation and approval of the manuscript, and decision to submit the manuscript for publication. The findings, interpretations, and conclusions expressed in this article do not necessarily reflect the views of the funder.

\section{Disclosure}

The authors report no conflicts of interest in this work.

\section{References}

1. Salerno F, Gerbes A, Ginès P, Wong F, Arroyo V. Diagnosis, prevention and treatment of hepatorenal syndrome in cirrhosis. Gut. 2007;56 (9):1310-1318.

2. Low G, Alexander GJM, Lomas DJ. Hepatorenal syndrome: aetiology, diagnosis, and treatment. Gastroenterol Res Pract. 2015;2015:11. doi:10.1155/2015/207012

3. Fernandez J, Navasa M, Planas R, et al. Primary prophylaxis of spontaneous bacterial peritonitis delays hepatorenal syndrome and improves survival in cirrhosis. Gastroenterology. 2007;133 (3):818-824.

4. Gines A, Escorsell A, Gines P, et al. Incidence, predictive factors, and prognosis of the hepatorenal syndrome in cirrhosis with ascites. Gastroenterology. 1993;105(1):229-236. doi:10.1016/0016-5085(93) 90031-7

5. Wong LP, Blackley MP, Andreoni KA, Chin H, Falk RJ, Klemmer PJ. Survival of liver transplant candidates with acute renal failure receiving renal replacement therapy. Kidney Int. 2005;68(1):362-370. doi:10.1111/j.1523-1755.2005.00408.x

6. Charatcharoenwitthaya P, Soonthornworasiri N, Karaketklang K, et al. Factors affecting mortality and resource use for hospitalized patients with cirrhosis: a population-based study. Medicine. 2017;96 (32):e7782. doi:10.1097/MD.0000000000007782

7. Poovorawan K, Treeprasertsuk S, Thepsuthammarat K, Wilairatana $P$, Kitsahawong B, Phaosawasdi K. The burden of cirrhosis and impact of universal coverage public health care system in Thailand: nationwide study. Ann Hepatol. 2015;14(6):862-868. doi:10.5604/ 16652681.1171773

8. Angeli P, Garcia-Tsao G, Nadim MK, Parikh CR. News in pathophysiology, definition and classification of hepatorenal syndrome: a step beyond the International Club of Ascites (ICA) consensus document. J Hepatol. 2019;71(4):811-822. doi:10.1016/j.jhep.2019.07.002

9. Alessandria C, Ozdogan O, Guevara M, et al. MELD score and clinical type predict prognosis in hepatorenal syndrome: relevance to liver transplantation. Hepatology. 2005;41(6):1282-1289. doi:10.1002/hep.20687

10. Planas R, Montoliu S, Balleste B, et al. Natural history of patients hospitalized for management of cirrhotic ascites. Clin Gastroenterol Hepatol. 2006;4(11):1385-1394. doi:10.1016/j.cgh.2006.08.007

11. European Association for the Study of the Liver. EASL clinical practice guidelines on the management of ascites, spontaneous bacterial peritonitis, and hepatorenal syndrome in cirrhosis. $J$ Hepatol. 2010;53(3):397-417. doi:10.1016/j.jhep.2010.05.004

12. Fagundes C, Gines P. Hepatorenal syndrome: a severe, but treatable, cause of kidney failure in cirrhosis. Am J Kidney Dis. 2012;59 (6):874-885. doi:10.1053/j.ajkd.2011.12.032

13. Baraldi O, Valentini C, Donati G, et al. Hepatorenal syndrome: update on diagnosis and treatment. World J Nephrol. 2015;4 (5):511-520. doi:10.5527/wjn.v4.i5.511

14. Gifford FJ, Morling JR, Fallowfield JA. Systematic review with meta-analysis: vasoactive drugs for the treatment of hepatorenal syndrome type 1. Aliment Pharmacol Ther. 2017;45(5):593-603. doi:10.1111/apt.13912 
15. Mattos AZ, Mattos AA, Ribeiro RA. Terlipressin versus noradrenaline in the treatment of hepatorenal syndrome: systematic review with meta-analysis and full economic evaluation. Eur $J$ Gastroenterol Hepatol. 2016;28(3):345-351. doi:10.1097/MEG. 0000000000000537

16. Working Group on the Guidelines for Health Technology Assessment in Thailand. Guidelines for Health Technology Assessment in Thailand. 1 ed. Nonthaburi, Thailand: The Graphico Systems Co., Ltd; 2009.

17. Working Group on the Guidelines for Health Technology Assessment in Thailand. Guidelines for Health Technology Assessment in Thailand. 2 ed. Nonthaburi, Thailand: Wacharin PP Printing LP; 2013.

18. Best LM, Freeman SC, Sutton AJ, et al. Treatment for hepatorenal syndrome in people with decompensated liver cirrhosis: a network meta-analysis. Cochrane Database Syst Rev. 2019;9(9):Cd013103.

19. Facciorusso A, Chandar AK, Murad MH, et al. Comparative efficacy of pharmacological strategies for management of type 1 hepatorenal syndrome: a systematic review and network meta-analysis. Lancet Gastroenterol Hepatol. 2017;2(2):94-102. doi:10.1016/S2468-1253(16) 30157-1

20. Weerayingyong P, Rattanavipapong W, Suwanthawornkul T, et al. The cost-utility analysis and budget impact analysis of chronic hepatitis $\mathrm{C}$ virus treatment (in Thai language). International Health Policy Program (IHPP) and the Health Intervention and Technology Assessment Program (HITAP); 2011.

21. Pachanee K, Wongphan T, Prakongsai P. Economic evaluation and budget impact analysis of liver transplantation among Thai adults in universal health insurance coverage in Thailand. JHS. 2016;25 (5):908-919.

22. Boyer TD, Sanyal AJ, Wong F, et al. Terlipressin plus albumin is more effective than albumin alone in improving renal function in patients with cirrhosis and hepatorenal syndrome type 1 . Gastroenterology. 2016;150(7):1579-1589.e1572. doi:10.1053/j. gastro.2016.02.026

23. Sharma P, Kumar A, Shrama BC, Sarin SK. An open label, pilot, randomized controlled trial of noradrenaline versus terlipressin in the treatment of type 1 hepatorenal syndrome and predictors of response. Am J Gastroenterol. 2008;103(7):1689-1697. doi:10.1177/ 0272989X03261568

24. Anukoolsawat P, Sritara P, Teerawattananon Y. Costs of lifetime treatment of acute coronary syndrome at ramathibodi hospital. Thai Heart J. 2006;19:132-143.
25. Thongsawat S, Piratvisuth T, Pramoolsinsap C, Chutaputti A, Tanwandee T, Thongsuk D. Resource utilization and direct medical costs of chronic hepatitis $\mathrm{C}$ in Thailand: a heavy but manageable economic burden. Value Health Reg Issues. 2014;3:12-18. doi:10.1016/j.vhri.2013.09.002

26. Wells CD, Murrill WB, Arguedas MR. Comparison of healthrelated quality of life preferences between physicians and cirrhotic patients: implications for cost-utility analyses in chronic liver disease. Dig Dis Sci. 2004;49(3):453-458. doi:10.1023/B: DDAS.0000020502.46886.c1

27. Russell RT, Feurer ID, Wisawatapnimit P, Pinson CW. The validity of EQ-5D US preference weights in liver transplant candidates and recipients. Liver Transpl. 2009;15(1):88-95.

28. Krahn M, Wong JB, Heathcote J, Scully L, Seeff L. Estimating the prognosis of Hepatitis $\mathrm{C}$ patients infected by transfusion in Canada between 1986 and 1990. Med Decis Making. 2004;24(1):20-29.

29. Reference drug price Jan-March 2015 (B.E. 2558): Average price of TERLIPRESSIN VIAL DRY 1 MG [page 130]. Drug and Medical Supply Information Center; 2016. Available from: http://dmsic.moph. go.th/index/download/569. Accessed 26 July, 2021. Thai.

30. Reference drug price Jan-March 2015 (B.E. 2558): Average price of NOREPINEPHRINE AMP [page 98]. Drug and Medical Supply Information Center; 2016. Available from: http://dmsic.moph.go.th/ index/download/569. Accessed 26 July, 2021. Thai.

31. Reference drug price Jan-March 2015 (B.E. 2558): Average price of ALBUMIN INFUSION 20 \% (50 ML) [page 3-4]. Drug and Medical Supply Information Center; 2016. Available from: http://dmsic.moph. go.th/index/download/569. Accessed 26 July, 2021. Thai.

32. Chatchawan $\mathrm{S}$. Unit cost in nakornping hospital Chiang Mai province (in Thai language). Lanna Public Health J. 2010;6(3):235-245.

33. Riewpaiboon A. Standard cost lists for health technology assessment. Bangkok: Tana Press Co., Ltd.; 2011.

34. Mattos AZ, Mattos AA, Ribeiro RA. Terlipressin versus noradrenaline for hepatorenal syndrome. Economic evaluation under the perspective of the Brazilian public health system. Arq Gastroenterol. 2016;53:123-126. doi:10.1590/S0004-28032016000200014

35. Runken MC, Caraceni P, Fernandez J, Zipprich A, Carlton R, Bunke M. The cost-effectiveness of albumin in the treatment of decompensated cirrhosis in Germany, Italy, and Spain. Health Econ Rev. 2019;9(1):22. doi:10.1186/s13561-019-0237-7
ClinicoEconomics and Outcomes Research

\section{Publish your work in this journal}

ClinicoEconomics and Outcomes Research is an international, peerreviewed open-access journal focusing on Health Technology Assessment, Pharmacoeconomics and Outcomes Research in the areas of diagnosis, medical devices, and clinical, surgical and pharmacological intervention. The economic impact of health policy and health systems organization also constitute important areas of coverage. The manuscript management system is completely online and includes a very quick and fair peer-review system, which is all easy to use. Visit http://www.dovepress.com/testimonials.php to read real quotes from published authors. 